\title{
A preliminary investigation of differences in acoustic startle responses between school-age children who do and do not stutter
}

\author{
Megan Kate Selman, Brent Andrew Gregg \\ Department of Communication Sciences and Disorders, University of Central Arkansas, Conway, Arkansas, USA
}

Purpose: It is theorized that stuttering emerges as the result of an interaction between constitutional and environmental factors and that constitutional factors in persistent stuttering may include an emotionally-reactive temperament. The purpose of this pilot study is to examine the reactive/"sensitive" temperament characteristic of children who stutter relative to children who do not stutter, as evidenced by the acoustic startle response and scores on the following subscales of a temperament measure: anger/frustration, fear, inhibitory control, and shyness.

Methods: Twenty seven school-age children participated in this study. There were thirteen children who stutter (CWS) and fourteen normally-fluent children. Participants were between the ages of 8:0 and 14:0. Each child participated in an acoustic startle response task, and caregivers completed a standardized temperament/personality assessment on their child.

Results: Results indicated that CWS do not demonstrate statistically significant higher levels of physiological reactivity, as measured by mean normalized RMS amplitude of startle response scores, compared to their fluent peers. Further, there was no statistically significant correlation between subscale scores on standardized temperament/personality assessments.

Conclusions: Improving on methodologies of past studies, the present investigation employed epidemiologically-sound groups, as well as clearly-delineated and replicable EMG procedures, normalization of EMG data, and neurophysiological measures of temperament combined with caregiver temperament questionnaire. Findings are in contradiction to several studies that have reported higher levels of trait anxiety or "nervousness" in adults who stutter. Keywords: Stuttering, Temperament, Startle response, EMG

\section{INTRODUCTION}

Stuttering is hallmarked by variability, both across the disorder as well as within the individual. Universally agreeing on a definition for the disorder is a controversial task at best-- allusive at the very least. The theoretical orientation for this study is based upon a dynamic, multifactorial model of stuttering, defining stuttering as a disorder involving complex, multilevel and dynamic linguistic, central speech programming, emotional, and cognitive processes that interact to ultimately affect the motor function necessary for speech production. This orientation views stuttering not as a single disorder-a pathognomic monolith-but instead one of immense diversity, persisting in some individuals and subsiding in others [1]. Once viewed as a solely unitary disorder and

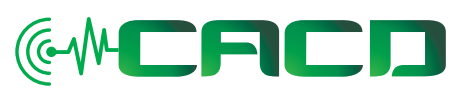

Received: May 19, 2020

Revision: September 1, 2020

Accepted: September 22, 2020

Correspondence:

Brent Andrew Gregg

Department of Communication Sciences and Disorders, University of Central Arkansas, Conway, Arkansas 72034, USA Tel: +501-852-2823

Fax: +501-450-5474

E-mail: bgregg@uca.edu

(C) 2020 The Korean Association of SpeechLanguage Pathologists

This is an Open Access article distributed under the terms of the Creative Commons Attribution NonCommercial License (https://creativecommons.org/ licenses/by-nc/4.0/) which permits unrestricted noncommercial use, distribution, and reproduction in any medium, provided the original work is properly cited. 
studied in isolation, stuttering now is recognized as a dynamic, complex, and multifactorial disorder. These factors include, but are not limited to, genetic predispositions, the effects of emotional and autonomic arousal on overt speech, and psychosocial aspects [2]. Psychosocial components of stuttering such as self-perceptions, parental perception of their children, and child-raising practices are emphasized in previous literature [3].

\section{Stuttering and temperament}

With regard to the various subtypes of stuttering, many current theoretical models include temperament as significantly influencing the developmental pattern of stuttering. Temperament refers to a set of behavioral characteristics or reactions that are biologically-based, present from infancy, and relatively stable over time and across contexts [4]. From this develops a constitutional relationship between emotional reactivity and emotional regulation. According to this definition, the individual differences in reactive and regulation manifest in domains of emotion, attention, and activity [4]. Rothbart [4] identifies surgency/extraversion, negative affect, and effortful control as the three dimensions of temperament based upon factor analysis on data from 3-12 month old children [5]. Temperament is a stable, trait-like characteristic that can manifest in a variety of emotional, state-like, ways. Therefore assessing the superficial emotions can lead to misrepresentations of temperament. Temperament is stable and interacts with stuttering as an attribute domain and not an ability domain (such as language or phonology). Temperament influences the speech disfluency as this may be a function of one's reaction or response to sensory stimuli.

Additionally, manifestations of stuttering are highly variable in the presence of environmental stimuli. Previous research has failed to control for the variable nature of both stuttering and temperament-driven emotional manifestations, as it has relied heavily on parent-report and clinical observations. In order to accurately assess temperament at a constitutional level in children who stutter, neuropsychological measures must be used to assess components of temperament such as reactivity, hyper vigilance, stress response, and emotional regulation.

Previous research suggests that children who stutter demonstrate increased emotional reactivity/sensitivity compared to their normally fluent peers [6,7]. Studies have shown that children who stutter may react more negatively to environmental stimuli $[6,8,9]$ and may demonstrate higher levels of impulsivity and activity [10]. Evidence also suggests children who stutter, as a group, demonstrate less emotional regulation $[9,11,12]$ adaptability, and inhibitory control $[11,10]$. The dimension of emotional reactivity, often referred to as "sensitivity," or exhibiting a "sensitive" temperament, has been of interest as it pertains to individuals who stutter [13-16]. Research literature has asserted that such a temperament may have constitutional roots, as well as direct links to persistent stuttering, and might interfere with early stuttering recovery [14-16]. There is evidence of increased positive and negative reactivity in individuals who stutter, as data indicates people who stutter exhibit heightened feelings of anxiousness, nervousness, helplessness, as well as dependence, introversion, negative social and/or communication attitudes, withdrawal, lower social competence, and mild social maladjustments [6,17-20].

Previous research confirms heightened reactivity in people who stutter is autonomic in nature $[7,21,22]$. In other words, this heightened reactivity is related to the autonomic nervous system and is not a reaction that is under the voluntary control of the individual. Data has shown speaking situations to produce higher levels of urine catecholamine excretion in people who stutter [23]. Ortega [21] examined salivary cortisol and alpha-amylase, two independent measures of stress response, in children who stutter. Ortega found children who stutter did not possess salivary cortisol levels outside of the normal limits expected for their ages. However, cortisol samples upon awakening, and in the afternoon, were significantly different in children who stutter, indicating CWS have more variable levels of cortisol throughout the day. Though cortisol and alpha-amylase levels were within normal limits, daily circadian rhythms were generally disrupted for both biomarkers [21]. These altered rhythms indicate nuances in the physiological stress response of children who stutter that differ from that of their normally fluent peers. Additionally, it was reported that people who stutter produced greater increases in salivary cortisol when compared to their normally fluent peers under periods of high general stress [24]. Multiple studies have indicated sympathetic arousal and stuttering severity to be positively correlated as well $[25,26]$. Treatment studies investigating individuals who stutter have found high anxiety, as measured by skin conductance, to be a poor prognosis for treatment outcomes [27]. Another physiological factor related to neuromuscular reactivity is calcium; nervous system excitability is enhanced and involuntary muscular contractions were found to increase when calcium levels were low in an individual [28]. 
This sheds new light on previous research findings by Costa, Antoniac, Berghianu, and Marinescu [29], who reported abnormally low levels of calcium among children and adults who stuttered. Recently, Alm [30] asserted that a state of heightened neuromuscular excitability would lead to muscular tension, rapid articulatory movements, and increased feelings of speech-related anxiety, all of which would confound problems of disfluent speech for an individual who stutters.

In addition, autonomic differences in individuals who stutter have been found in neurologic research domains. The physiological differences have emotional implications as well. Brown, Ingham, Ingham, Laird, and Fox's [31] seminal fMRI study found a clear deactivation in Broca's Area, a left hemisphere substrate, in individuals who stutter during spontaneous speech. Simultaneously, a significant increase of inappropriate activation was found in the corresponding area of the right hemisphere, the so-called Anterior Area of Ross, in these individuals. The Anterior Area of Ross in the right hemisphere mirrors the location of Broca's Area in the left hemisphere. The Anterior Area of Ross is the seat of expressive prosody in speech. This area receives input from the emotional centers of the limbic system. Therefore, a fearful and hyper-emotional speaking situation would result in inappropriate activation of the prosodic centers within the right hemisphere during speech. Inappropriate activation of the right hemisphere during speaking tasks in individuals who stutter has been confirmed in multiple studies dating back to the SPECT studies of the 1980's [32-34]. The inappropriate activation of right hemispheric emotional centers during speaking tasks has profound implications for people who stutter in that these structures have deep-seated neurological connections with the limbic system, a structure highly susceptible to classical conditioning, as well as the hippocampus, which is the sub-cortical seat for memory. This sheds light on aspects of emotionality and emotional learning that may be influencing disfluent speech.

Therefore, emotional responses can be learned and hardwired into the neurological reactions of individuals with fluency disorders. Emotional pathways may be established that produce fear, anxiety, or disappointment as familiar, conditioned responses. Compounding the problem is the fact that frequent experiences with fluency failures are not uncommon for individuals who stutter. The negative experiences create additional opportunities for repeated negative reactions. Additionally, having a temperamental characteristic of poor emotional regulation would thus put an individual who stuttered at a disadvantage for mitigating his/her fear response.
Thus, the cognitive belief system of the individual is subsequently impacted to a great extent as they struggle with, not only fluent speech, but also this compounding problem of an ingrained, internal fear response to speaking situations. Each fluency failure reinforces beliefs that for this individual, speaking is difficult, and should be feared, and thus a cyclical effect occurs as each new experience confirms this negative belief system [35].

\section{Weaknesses of past research}

Internal emotions and neuromuscular patterns can manifest in exaggerated muscular reflexes and difficulties in regulating force and speed during speech for individuals who stutter. This assertion is supported by a report of increased "acoustic startle" in persons who stutter, as measured by increased eyeblink reflexes in response to a surprising, loud noise [36]. Participants in this study were male and female adults, ranging in stuttering severity from mild to severe. Startle responses are determined by exposing the listener to a surprising acoustic, tactile, or visual stimulus of sufficient strength, and measuring the changes that result in the individual's somatic system (i.e., muscular contractions such as the eye-blink reflex) [37]. The acoustic startle response has been used in research within the domain of psychophysiology, specifically related to the study of emotional development and modification [38]. The amplitude of the startle response is directly moderated by an individual's current emotional state [39] and increases in response to negative stimuli as well as anticipatory anxiety [40]. Multiple research findings indicate that individuals with increased emotional vulnerability often present with an increased amplitude of startle response, such as adults or children with anxiety disorders, posttraumatic stress syndrome, or other psychiatric abnormalities [41]. Previously, Guitar [36] reported adults who stuttered to have an $81 \%$ higher mean amplitude of startle response compared to their normally fluent peers. This percentage was based upon 14 adults who stutter and 14 adults who do not stutter reacting to bursts of white noise at approximately $95 \mathrm{~dB}$. Additionally, data from this study showed a significant difference between the adults who stuttered and the adults who did not stutter in the "Nervous subscale" of the Taylor-Johnson Temperament Analysis [42]. Guitar also found evidence to support a statistically significant positive correlation ( $r=0.39, p=0.04$ between the amplitude of startle eye blink response and Nervous subscale scores.

Zimmerman [43-45] and others have suggested stuttering to be related to increased activity in the reflexes of the brain- 
stem. The acoustic startle is a reflexive contraction of the orbicularis oculi muscle activated by the fast fear system. The neurological fast fear system bypasses the frontal lobes of the left and right hemispheres and courses from the sensory areas to the thalamus, amygdala, and limbic system. This fast fear system is responsible for our physiological response to fearinducing stimuli and this reaction cannot be altered. In contrast, the slow fear system includes the frontal lobes of the left and right hemisphere as it courses from the sensory areas to the thalamus, frontal lobes, and amygdala. The slow fear system can be attended to and cognitively controlled and can subsequently influence fear behavior through rationale, reasoning, and problem solving. The fast fear system is an automatic, physiological response and can be expressed in a reflexive reaction, such as the startle response [35].

The startle response occurs 30-50 ms after the presentation of a sound stimulus [37]. Davis, Walker, and Lee [46] described the startle response to be potentiated by fear-related signals from the amygdala and surrounding substrates to the brainstem. Therefore, further and systematic examination of the startle response in individuals who stutter might provide insight into brainstem activity related to speech motor control, neuromuscular and sensorimotor reactivity, and autonomic temperamental factors in individuals who stutter. Specifically, there is a need for empirical evidence measuring the aforementioned components within the pediatric stuttering population of people who stutter in order to better understand attributes of primary personality traits (i.e., more naturally anxious, independent of stuttering), and traits secondary to stuttering (i.e., more anxious because they stutter), as well as to differentiate subtypes within the developmental disorder. By examining the temperament of school-age children who stutter, a persistent group of children who stutter can be identified and studied at an early age. Older populations begin to accumulate years of negative stuttering experiences, which can shape their temperament and emotional reactions over time. Thus, it is crucial to study children who are beyond the years of recovery and have yet to accrue a number of years of negative emotional experiences relative to their disfluent speech.

Previously, studies of temperament have relied heavily on parent questionnaire and self-report. While these measures provide important information regarding an individual's predispositions and temperamental tendencies, a level of human error is present. Additionally, past studies have found large discrepancies between parent-report and child-report on measures of quality of life [47], relationship quality [48], psy- chosocial health domains [49] as well as emotional and mental health domains [50]. Therefore, when examining aspects of a child's psychosocial profile, such as temperament, it is critical to administer more than a single parent questionnaire. Self-report measures are also subject to confounding variables which are difficult to identify and control, such as cognitive perspective, situational perspective, and the stable cognitive profile of the individual [51]. There is a need to include objective measures, such as physiological measures, when investigating the relationship between reactive temperament and persistent stuttering. Thus, pairing a parent questionnaire with a physiological measure, such as the acoustic startle response, will more accurately establish a neurophysiologic basis in a field that relies heavily on self-report and questionnaire.

To date, there has yet to be a physiological study of temperament conducted within the population of school-aged children who stutter. Such a study could objectively differentiate characteristics of stuttering intrinsically related to reactivity verses self-regulation strategies adopted by the autonomic nervous system as coping mechanisms. Previous research conducted by Guitar [36] and Alm [37] investigating the acoustic startle reflex in individuals who stutter failed to normalize the EMG portion of their data. In order to accurately reflect the intensity of an individual's response to startling stimuli, the response must be viewed relative to the individual's baseline eye-blink under normal conditions. Normalization allows data across participants to be compared on a common scale, as participant's response amplitudes are expressed in terms of percentage of baseline response. This methodological aspect is critical to accurately detect the intensity of reactions across subjects, and draw meaningful conclusions. Therefore, researchers must employ normalization procedures when interpreting EMG activity level, by relating it to some reference activity level obtained at that particular muscular injunction, in this case baseline eye-blinks under natural conditions. Previous research lacking data normalization cannot accurately represent the amplitude of the startle response comparatively across individuals, leading to the possibility of unreliable conclusions.

\section{Implications for current study}

The purpose of this pilot study is to examine the reactive/ "sensitive" temperament characteristic of children who stutter relative to children who do not stutter, as evidenced by the acoustic startle response and scores on the following subscales of a temperament measure: anger/frustration, fear, in- 
hibitory control, and shyness. The acoustic startle response is widely used as a measure of the reflexive eye blink that occurs innately in response to sudden and/or loud noise [52,53].

Pairing these two measures, one direct and one indirect, will provide insight into the link between temperamental factors and fluency disorders within the pediatric population. Research in this area supports both physiological and descriptive temperamental differences in children who stutter and children who do not stutter [10,15,54-59]. However, these two methods are rarely combined effectively within the design of a singular study, resulting in less-than-comprehensive results relative to temperament.

It remains to be determined if certain temperamental differences are inherent to individuals who stutter, or perhaps a result of the stuttering itself. For example, counter-intuitive findings by Alm $[30,60]$ showed individuals who stutter to have a reduction in heart rate and blood pressure when compared to their normally fluent peers. Alm postulated this could be due to a co-activation of autonomic nervous system branches that are responding to communication induced stress and anxiety, indicating that such a response was an attempt at self-regulation. Alm [60] suggested that this autonomic response possibly resulted in momentary static posturing within antagonistic muscle-groups, interrupting the forward flow of speech in stressful contexts. Examining the emotional reactivity of children who stutter using physiological measures, such as the acoustic startle response, would allow researchers to parse out characteristics of stuttering inherent to reactivity verses self-regulation strategies adopted by the autonomic nervous system as coping mechanisms.

To date, few physiological studies of temperament have been conducted on a pediatric population within individuals who stutter. The need for examining a pediatric population is evident, as older populations have several additional years of negative stuttering experiences shaping their temperamental disposition and emotional reactions. Studying a group of children ages 8-14, excludes individuals who may recover from stuttering, as the majority of children who exhibit natural recovery within a few months to three or four years after they begin stuttering, and typical age of onset is between 25 and 36 months [3]. Therefore, the design of this study allows for the isolation of the persistent subgroup of children who stutter and comparison with their normally fluent peers.

\section{Research questions}

1. Will CWS demonstrate statistically significant higher levels of physiological reactivity, as measured by mean normalized RMS amplitude of startle response scores, compared to their fluent peers?

2. Will CWS demonstrate a statistically significant higher level of physiological reactivity, as measured by mean latency of startle response scores, than their fluent peers?

3. Will CWS demonstrate statistically significant higher levels of physiological reactivity, as measured by the difference between initial and final stimulus trial response amplitudes (i.e., habituation rate, which is the decrease in response to a stimuli after repeated presentations), compared to their fluent peers?

4. Will there be a statistically-significant and meaningful correlation between scores on the anger/frustration, fear, inhibitory control, and shyness subscales of the EATQ-R and TMCQ, and amplitude (or extent of muscle activity) of startle response?

\section{METHODS}

\section{Participants}

Twenty seven school-age children participated in this study. There were thirteen CWS and fourteen CWNS. The ratio of male to female CWS was controlled in the stuttering group in order to represent the long-known gender ratio within this disorder [1]. A male-to-female ratio is close to 2:1 at onset for CWS, but increases to $5: 1$ or 6:1 as children age, indicating that more females than males recover as time goes by [61]. Participants were between the ages of 8:0 and 14:0. Data indicate that $75 \%$ of children who stutter eventually recover and become normally fluent speakers [1], with a majority of these children spontaneously recovering by age 4 , though a small percentage of children experience recovery later with stuttering remitting around age 5. Therefore, the age group of participants in this study was representative of children who are on the persistent track of stuttering.

Ethnicity was left free to vary, as data indicate that this disorder is fairly stable across race and ethnicity [3]. Children who live within 50 miles of the Central Arkansas area were eligible for participation. The participants in the stuttering group were recruited from the University of Central Arkansas Stuttering Center and surrounding school districts. The participants in the nonstuttering group were recruited using wordof-mouth and were free from any speech, language learning, and hearing impairment. In order to participate, all children were required to pass a hearing screening, or provide evi- 
dence of a current passed hearing screening. Any child who failed to demonstrate hearing abilities within normal limits were not included.

\section{Inclusion criteria}

In view of the multidimensionality of stuttering, there is some ambiguity in specifically defining the disorder. For the purposes of this research, a diagnosis of stuttering was validated using the following inclusion criteria (adapted from the University of Illinois Stuttering Research Program):

A. Parents diagnosed the child as having a stuttering problem. Parents were given a stuttering severity rating scale and instructed how to appropriately complete it. A parent rating of at least 2 on this 8 point scale was required $(0=$ normal, $7=$ severe).

B. The primary investigator and her doctoral mentor both agreed that the child had a stuttering problem or diagnosis based on subjective observations.

C. Stuttering severity was rated by both the primary investigator and by the research mentor as greater than 1 on the aforementioned 8 point scale $(0=$ normal, $1=$ borderline, $7=$ very severe).

D. The child exhibited at least three stuttering-like disfluencies (SLDs) per 100 syllables of spontaneous speech (SLDs include part-word repetitions, monosyllabic word repetitions, and disrhythmic phonations). This criterion reflects the opinion of many speech-language pathologists that young children whose speech includes these type of disfluencies this frequently are stuttering [62] and is consistent with the disfluency data reported by Johnson et al. [63] for a large number of children who stutter.

E. The child had no reported history of neurological disorder or abnormalities. Children with a major organic condition were excluded because their condition may overshadow the dynamics of stuttering that are being studied.

\section{Pre-Assessment}

The Stuttering Severity Instrument, Third Ed (SSI-3) [64] was administered to assess the severity of stuttering by participants in the stuttering group. The Stuttering Severity Instrument, Third Ed (SSI-3) [64] is a reliable and valid norm-referenced stuttering assessment that can be used for both clinical and research purposes. It measures stuttering severity in both children and adults in the four areas of speech behavior: (1) frequency, (2) duration, (3) physical concomitants, and (4) naturalness of the individual's speech. Frequency is expressed in percent syllables stuttered and converted to scale scores of 2-18. Duration is timed to the nearest one tenth of a second and converted to scale scores of 2-18. The four types of Physical Concomitants are and converted to scale scores of 0-20.

\section{Participant groups Individual data of participants}

Twenty-seven school-age children completed both portions of this study, which included EMG analysis of startle response, as well as completion of a parent-report questionnaire. These children were separated into two groups: CWS and CWNS.

\section{Children who stutter}

The group of CWS was comprised of thirteen children, ranging in age from 8-14, with a mean age of 10.6. Of the CWS, two were female and ten were male. This approximated a 3:1 male to female ratio, which accurately represented the male to female ratio previously established for school-age CWS [3]. The mean clinician severity rating for CWS was 3.06 , which is indicative of a moderate stuttering disorder. The mean parent severity rating was 3.62 , also indicative of a moderate stuttering disorder. The average difference between clinician and parent severity ratings was 0.56 . This indicated the stuttering observed by the clinician during the severity rating session was an accurate representation of the child's stuttering across multiple settings with both familiar and non-familiar partners. Additionally, this is an indication that parents of participants in this study are well educated about the characteristics and nature of their child's disfluent speech; thus, information provided by parents during parent interviews is well-founded.

\section{Children who do not stutter}

The group of CWNS was comprised of fourteen children, ranging in age from 8-13, with a mean age of 11.6. Of the CWNS, four were male and nine were female. Since gender is not a significant factor in children who speak fluently, this male to female ratio was selected in order to balance out the overall number of male and female participants in this study.

Overall, the participants' age ranged from 8 to 14 years of age, with a mean age of 11.07 years. Fourteen males and thirteen females participated. Homogeneity of variance and normality were tested using Levine's Test for Equality of Variance and no significant differences were found between the two groups. Data for each group of participants are presented in Tables 1 below.

Individual data from Table 1 indicates the mean age of CWS 
Table 1. CWS: Individual Data, Means, and Standard Deviations for: Age, Gender, and Severity of Stuttering Disorder According to Clinician and Parent Rating

\begin{tabular}{lccccc}
\hline Subject & Age (yr) & Gender & Stutter & $\begin{array}{c}\text { Clinician } \\
\text { Rating }\end{array}$ & $\begin{array}{c}\text { Parent } \\
\text { Rating }\end{array}$ \\
\hline P1 & 10 & M & Y & 1.25 & 3 \\
P2 & 8 & F & Y & 2.25 & 3.5 \\
P3 & 9 & M & Y & 3.5 & 3.5 \\
P4 & 14 & M & Y & 3 & 3 \\
P5 & 8 & M & Y & 1.41 & 4 \\
P6 & 11 & M & Y & 2.8 & 3 \\
P7 & 11 & M & Y & 3.66 & 3 \\
P8 & 11 & F & Y & 2.25 & 3 \\
P9 & 10 & M & Y & 3.66 & 3 \\
P10 & 10 & F & Y & 2.08 & 6 \\
P11 & 14 & M & Y & 2.6 & 5 \\
P12 & 12 & M & Y & 5.32 & 2 \\
P13 & 11 & M & Y & 6.08 & 5 \\
\hline
\end{tabular}

was 10.7 years old. Eleven males who stutter and two females who stutter participated, which approximated the 3:1 gender ratio previously established for school-aged CWS [3]. The mean clinician severity rating was 3.06 , indicating a moderate stutter. The mean parent severity rating was 3.62 , also indicating moderate stuttering.

Individual data from Table 2 indicates the mean age of CWNS was 11.4 years old. Four males and ten females who do not stutter participated. Stuttering behaviors were not present in this group of participants.

\section{Procedures}

Prior to data collection, all inclusion criteria measures and/or pre-assessment measures were completed. All EMG laboratory equipment, including hardware and software were calibrated. Prior to arriving at the testing session, participants and their caregiver were educated about the experiment and its purpose(s). The participant were informed that the experiment would involve a task in which they would hear brief bursts of noise. Participants and their parents were then asked to review a lay summary of the procedures and sign a consent form. All testing was performed individually.

Participants entered a testing room and headphones were fitted for the startle stimulus. Participants were asked to sit silently and gaze at a spot on the wall, so that baseline data could be collected relative to the individual's natural eye-
Table 2. CWNS: Individual Data, Means, and Standard Deviations for: Age, Gender, and Severity of Stuttering Disorder According to Clinician and Parent Rating

\begin{tabular}{lccccc}
\hline Subject & Age (yr) & Gender & Stutter & $\begin{array}{c}\text { Clinician } \\
\text { Rating }\end{array}$ & $\begin{array}{c}\text { Parent } \\
\text { Rating }\end{array}$ \\
\hline P14 & 10 & F & N & 0 & NA \\
P15 & 8 & M & N & 0 & NA \\
P16 & 9 & M & N & 0 & NA \\
P17 & 14 & M & N & 0 & NA \\
P18 & 11 & M & N & 0 & NA \\
P19 & 12 & F & N & 0 & NA \\
P20 & 12 & F & N & 0 & NA \\
P21 & 12 & F & N & 0 & NA \\
P22 & 12 & F & N & 0 & NA \\
P23 & 11 & $F$ & $N$ & 0 & NA \\
P24 & 12 & $F$ & $N$ & 0 & NA \\
P25 & 11 & $F$ & $N$ & 0 & NA \\
P26 & 13 & $F$ & $N$ & 0 & NA \\
P27 & 13 & $F$ & $N$ & 0 & NA \\
\hline
\end{tabular}

blink. Approximately 20 eye blinks were recorded under natural conditions, without auditory stimuli. Participants were informed they would hear a series of white noise bursts (at this point the sound will be imitated by the researcher) separated by randomly chosen intervals between 20 and 30 seconds [36]. Participants were not informed how many noise bursts were in the series. The series of noise burst consisted of approximately 20 bursts of white noise, in order to elicit 20 eye blinks [36].

Participants were instructed to sit silently and remain still, directing their attention to the wall in front of them as they heard the noise bursts. Startle reflexes were recorded using EMG data collection procedures described below. After completing the startle task, the caregiver was asked to complete a temperamental assessment scale. This was administered by the primary investigator of this study.

\section{Startle apparatus and stimuli}

Baseline eye blink data was collected using a handheld trigger and open/close switch. This push-button trigger was integrated with LabView software to mark blinks based on visual observation by the investigator. Offline analysis blinks were located later manually in order to quantify events. Multiple baseline blinks (10) were recorded using these techniques, prior to the recording of an individual's startle response. This 
information was analyzed and a mean baseline (i.e., normal blink) response was established. Acoustic stimuli consisted of a 95- $\mathrm{dB}$ burst of white noise presented for $50 \mathrm{~ms}$ with a 10-ms rise and fall time. Multiple startle responses (10) were then recorded and analyzed to derive response means as well as standard deviations for each participant. Startle responses were analyzed using the audio stimulus as an onset and Delsys Smart Threshold procedures to determine response offset. These parameters were based on long-standing protocol for startle reflex analysis [52], as well as procedures followed in previous research [36]. This burst were presented binaurally through Beyerdynamic DT 48 A.00 headphones.

Stimuli was presented and responses were collected using a custom-written software program. This software program was designed using a LabView template that allowed for the administration of white noise bursts as well as the display of EMG and trigger data. A National Instruments USB-6008 data acquisition device as well as a Grass amplifier was used to collect electromyographic data as well. Startle responses were detected electromyographically using miniature $2 \mathrm{~cm}$ silversilver chloride electrodes placed on the periorbital area on the skin below the right eye. Gereonics electrodes were used in this study. Electrodes were trimmed, collared, and gelled. This is in accordance with procedures for orbicularis oculi placement given by Guitar [36] as well as Fridlund and Cacioppo [65]. The electrodes were placed exactly $2 \mathrm{~cm}$ apart, with a reference electrode stationed on the forehead of the individual. The electromyographic signals then were filtered between 30 and 1,000 Hz. Responses were detected during a 200-ms window that began at the instant of the startle stimulus presentation. Auditory acoustic stimuli consisted of approximately 95 $\mathrm{dB}$ burst of white noise presented for $50 \mathrm{~ms}$. The sampling rate remained at $2,000 \mathrm{~Hz}$, contributing to the reliability of the EMG signal. This burst was presented binaurally through Beyerdynamic DT 48 A.00 headphones. These procedures were consistent with procedures recommended by researchers in the field of psychology for use of the startle paradigm [52]. Inter-electrode distance was carefully controlled for each participant in order to prevent this from influencing startle amplitudes. Currently, research on children between the ages of 6 and 12 suggests that body size or muscularity does not influence startle amplitudes [36].

In order to control for a large range of inherent differences in individual muscle size and tissue distribution, as lipose acts as a low-pass filter, all EMG startle responses were normalized in this study. These differences make it difficult to discern meaningful comparisons across individuals. Additionally, reflexes can be highly variable across individuals. Normalization is a process that is frequently used in EMG research in order to control for these differences. The electromyogram is the sum of the motor unit activity within a specific contraction at a given electrode location. This activity is then expressed in millivolts by the data collection instruments used in this study. EMG normalization expresses the millivolts of activity as a percentage. The percentage is representative of that muscle's activity during a test contraction relative to baseline contraction measures (reference voluntary contractions). Therefore, in this study the startle was expressed as a percent of contraction relative to an individual's normal (baseline) eye blink. Additionally, all responses were recorded during a single session for each individual. This contributed to the reliability of these findings.

\section{Normalization}

Startle response were normalized in this study to control for individual differences. The electromyogram (EMG) is the sum of the motor unit activity within a specific contraction at a given electrode location. This activity is then expressed in millivolts by the data collection instruments used in this study. EMG normalization expresses the millivolts of activity as a percentage. The percentage is representative of that muscle's activity during a test (startle) contraction relative to baseline contraction measures (reference voluntary contractions). Therefore, in this study, the startle was expressed as a percent of contraction relative to an individual's normal (baseline) eye blink. Thus, in order to accurately convey startle amplitude responses, the mean startle response was divided by the mean baseline response in order to produce the normalized startle response.

Normalization is critical as it controls for variables such as electrode application and placement, temperature, perspiration, muscle fatigue, contraction velocity, muscle shape and length, crosstalk from neighboring muscles, fat tissue thickness, and slight variations in task executions. It would be impossible to control all of these variables of EMG amplitude in a clinical setting. Normalization controls for the aforementioned variables and facilitates the comparison of EMG signals in a more accurate manner. Expressing the neural activity (EMG amplitude) as a percentage makes interpretation of the signal more meaningful and significant.

All previous studies $[36,37,60]$ concerning the startle reflex in individuals who stutter failed to include data normalization 
procedures within the methodology. This poor EMG technique can easily lead to misinterpretations of data. For example, a startle response of $148 \mathrm{mV}$ (averaged across 10 trials) across two individuals (Participant A and Participant B) would be interpreted as the same response according to the methodology employed by Guitar [36], Alm [60], and Alm and Risenburg [37]. However, upon further examination, Participant A's baseline eye blink might have been $100 \mathrm{mV}$ (mean) while Participant B's baseline eye blink might have been $140 \mathrm{mV}$ (mean). Normalization procedures would have revealed Participant A's startle response to be $150 \%$ greater than his/her normal eye blink, while Participant B's startle is exactly the same as his/her normal eye blink. In this example, normalizing the data reveals a significant difference between the startle responses of the two individuals. Without normalization procedures, this data is easily misinterpreted and meaningful analysis cannot occur. All data is arbitrary and does not allow for individual characteristics affecting signal amplitude, such as fatty tissue, muscle distribution, and reflex variation. Thus resulting conclusions are rendered irrelevant as well.

\section{Reliability}

In order to ensure reliability in EMG procedures several variables were kept consistent throughout these procedures. The sampling rate remained at 2,000 Hz, contributing to the reliability of the EMG signal. Additionally, electrode placement and skin preparations were carefully monitored in order to ensure consistency. Skin preparation consisted of cleaning the skin above the orbicularis oculi with an alcohol swab in order to remove any dirt or dead skin cell particles that would interfere with the surface electrode signal. Multiple baseline blinks (10) as well as multiple startle responses (10) were recorded and analyzed in order to derive response means as well as standard deviations for each participant. Outliers were defined as responses that were beyond two standard deviations of the mean. In this way, reliable muscle activation data was collected. Additionally, all responses were detected during a single session for each individual. This contributed to the reliability of this study.

\section{Temperament scales}

The Temperament in Middle Childhood Questionnaire (TMCQ) [66] and the Early Adolescence Temperament Questionnaire-Revised, Parent Report (EATQ-R) [67] were administered in order to measure individual temperament. These measures were used to assess the reactivity of participants in this study. They are "paper and pencil" parent questionnaires. It was necessary to use both measures in order to accommodate the 7:0 to14:0 age range of participants in this study. These measures were developed at the University of Oregon by Rothbart and are statistically significantly correlated with one another [68,69].

These measures were the best-fit for this current study because they explicitly test the aforementioned three dimension of temperament: surgency/extroversion, negative affect, and effortful control. The subscales for the TMCQ and EATQ-R that were used for the purposes of this examination were: anger/frustration, fear, inhibitory control, and shyness. The anger/frustration and fear subscales were designed to specifically reflect components of negative affect. The inhibitory control subscale was designed to specifically reflect aspects of effortful control within the child's temperament. The shyness subscale addressed surgency/extroversion. These aspects of temperament are complex and must be finely-differentiated. These measures were developed by Rothbart, whose research identified, defined, and subsequently developed accurate assessment measures for specifically examining these dimensions of temperament [68,69].

The Temperament in Middle Childhood Questionnaire (TMCQ) [66] is appropriate for participants age 7-10. This test is a highly differentiated assessment of temperament in middle childhood. Temperament dimensions for TMCQ scales were developed and adapted from dimensions for both adults and infants via the Children's Behavior Questionnaire (CBQ) [70], Hampton Individual Differences Questionnaire [71], the Childhood Temperament and Personality Questionnaire (CTPQ) [72], and the Children Behavioral Questionnaire Bipolar I (CBQ-BPI) [73,74]. This 157-question form identifies four factors of temperament, labeled: (1) Negative Affectivity, (2) Surgency Extraversion, (3) Effortful Control, and (4) Sociability/Affiliation.

The Early Adolescence Temperament Questionnaire-Revised, Parent Report (EATQ-R) [67] is a 62-item parent-questionnaire appropriate for participants ages 9-15. The questionnaire has been designed to specifically tap experiences common to adolescents and is available in self- and parentreport formats. The parent-report was used for the purposes of this study. This measure assessed temperament, reactivity, and self-regulation. The revised questionnaire also contained two behavioral scales to allow examination of the relationship of temperament to social-emotional functioning. 


\section{Subscales}

For the purposes of this study, data from the following subscales, which are common to both the EATQ-R and TMCQ, were analyzed: anger/frustration, fear, inhibitory control, and shyness. A five-point rating scale was used by the parent to answer each item on the test. Parents were asked to describe how true or false a statement is by circling a " 1 " for "almost always untrue of your child", a "2" for "usually untrue of your child", a " 3 " for "sometimes true, sometimes untrue of your child", a " 4 " for "usually true of your child", and a " 5 " for "almost always true of your child". Each dimension received an average rating (1-5) indicating the mean response given by the parent for each item within a specific dimension. These responses were calculated and compared between the two groups of participants.

\section{Data analysis}

\section{Differences in group demographics}

Participants were matched for age and gender respectively, across groups. No significant differences existed in terms of demographic data.

\section{Independent and dependent variables}

For the purposes of this study, the dependent variables consisted of three group comparisons: (1) mean response amplitude across 10 trials, (2) mean response latency across 10 trials and (3) difference between initial and final stimulus trial response amplitudes (i.e., habituation rate), (4) subtest scores on parent-report temperament assessment. These constituted the dependent variables for this study. The independent variable for this study was children who stutter.

\section{Variable analysis summary}

All subject data was coded and the primary investigator was blinded to files during the analysis process. Baseline data was further blinded and analyzed twice to establish a Pearson Correlation. Shapiro-Wilk test statistics and Levene's test statistics were calculated for each comparison to confirm normality and homogeneity of variance, respectively, between groups. Nonsignificant $p$ values for these tests indicated the distribution of data was sufficiently normal and variances in mean amplitude and mean latency of acoustic startle responses were comparable between groups.

The means and standard deviations of the stuttering and non-stuttering group were noted. Data was recorded in terms of amplitude of eye-blink response, which is given in analog- to-digital units. Independent t-tests were used to test for the presence of significant differences between startle amplitude between the two groups. A paired t-test was used to compare the differences between the first response and the 10th response within each individual to examine habituation differences.

The means and standard deviations for the EATQ-R and TMCQ subscales were recorded for the stuttering and nonstuttering group. Pearson-produce-moment correlations tested for significant correlation between the sub scales and the mean amplitude of the response for individuals within stuttering and nonstuttering group.

\section{Differences in startle response}

As a measure of startle response, EMG waves were analyzed and the following summary variables were provided to compare across groups. To determine the difference in startle response between group mean amplitude and latency, standard deviations were analyzed.

Shapiro-Wilk test statistics and Levene's test statistics were calculated for each of these comparisons to confirm normality and homogeneity of variance, respectively, between groups. Nonsignificant $p$ values for these tests indicated the distribution of data were sufficiently normal and variances in mean amplitude, mean latency, and habituation rate of acoustic startle responses were comparable between groups. The means and standard deviations of the stuttering and non-stuttering group were documented. Data was reported in terms of amplitude of eye-blink response, which was given in analogto-digital units. Independent t-tests were used to test for the presence of significant differences between startle amplitude between the two groups. A t-test was used to compare the differences between the first response and the 10th response within each individual to examine habituation differences.

\section{Differences in temperament scores}

To determine if there were differences in temperament between the group of children who stutter and the group of children who were fluent, the investigator first examined the temperament scale for each dimension of the questionnaire listed above. The means and standard deviations for the EATQ-R and TMCQ subscales were reported for the stuttering and non-stuttering group. Pearson-produce-moment correlations tested for significant correlation between the sub scales and the mean amplitude of the response for individuals within stuttering and nonstuttering group. 


\section{RESULTS}

The main objective of this study was to examine the relationship between pervasive stuttering and the acoustic startle response in school-age children. Four research questions were posed. First, this study examined whether CWS demonstrated statistically significant higher levels of physiological reactivity, as measured by mean normalized RMS amplitude (extent of muscle activity) of startle response scores, compared to their fluent peers. In order to answer this question, the startle responses of school-age children who stutter were measured using EMG analysis, then compared to the startle responses of CWNS using the same EMG procedures. The second question addressed the level of physiological reactivity, as measured by mean latency of startle response scores, between these two groups. While the first research question compared amplitude (intensity of muscle activity) of responses between CWS and CWNS, this subsequent question compared the latency (duration of muscle activity) of those responses. The data from these two questions were statistically analyzed using an independent sample t-test. Third, levels of physiological reactivity, as measured by the difference between initial and final stimulus trial response amplitudes (i.e., habituation rate, which is the decrease in response to a stimuli after repeated presentations) were measured and compared between groups using a paired sample t-test. Lastly, the relationship between scores

Table 3. Group Statistics and Independent Sample t-tests for Children Who Do and Do Not Stutter

\begin{tabular}{lccrrrr}
\hline Group Statistics & Stutter (Y/N) & N & Mean & Std. Deviation & Std. Error Mean \\
\hline Normalized Startle & Y & 14 & 1.7522 & 0.93485 & 0.24985 \\
Baseline Mean of Delta X & N & 13 & 1.7468 & 0.66901 & 0.18555 \\
& Y & 14 & 135.663214 & 55.9253411 & 14.9466761 \\
Startle Mean Delta X & N & 13 & 126.990623 & 61.9509802 & 17.1821104 \\
Baseline Mean of Mean & Y & 14 & 295.80093 & 265.567498 & 70.975899 \\
& N & 13 & 239.74623 & 141.936717 & 39.366162 \\
Startle Mean of Mean & Y & 14 & 111.55707 & 17.924607 & 4.790553 \\
& N & 13 & 100.42669 & 22.812093 & 6.326936 \\
\hline
\end{tabular}

Table 4. Group Statistics and Independent Sample t-tests for Children Who Do and Do Not Stutter Cont'd

\begin{tabular}{|c|c|c|c|c|c|c|c|c|c|c|}
\hline & & \multicolumn{2}{|c|}{$\begin{array}{c}\text { Levine's Test } \\
\text { for Equality of } \\
\text { Variances }\end{array}$} & \multicolumn{7}{|c|}{ t-test for Equality of Means } \\
\hline & & \multirow[t]{2}{*}{$F$} & \multirow[t]{2}{*}{ Sig. } & \multirow[t]{2}{*}{$t$} & \multirow[t]{2}{*}{$d f$} & \multirow[t]{2}{*}{$\begin{array}{c}\text { Sig. } \\
\text { (2-tailed) }\end{array}$} & \multirow[t]{2}{*}{$\begin{array}{c}\text { Mean } \\
\text { Difference }\end{array}$} & \multirow[t]{2}{*}{$\begin{array}{l}\text { Std. Error } \\
\text { Difference }\end{array}$} & \multicolumn{2}{|c|}{$\begin{array}{l}95 \% \text { Confidence } \\
\text { Interval of the } \\
\text { Difference }\end{array}$} \\
\hline & & & & & & & & & Lower & Upper \\
\hline \multirow[t]{2}{*}{ Normalized_Startle } & Equal var assumed & 8.351 & 0.008 & 0.017 & 25 & 0.986 & 0.00541 & 0.31510 & -0.64356 & 0.65438 \\
\hline & Equal var not assumed & & & 0.017 & 23.538 & 0.986 & 0.00541 & 0.31121 & -0.63757 & 0.64839 \\
\hline \multirow[t]{2}{*}{ Baseline Mean of Delta X } & Equal var assumed & 0.317 & 0.579 & 0.382 & 25 & 0.705 & 8.6725912 & 22.6841200 & -38.046 & 55.3914 \\
\hline & Equal var not assumed & & & 0.381 & 24.227 & 0.707 & 8.6725912 & 22.7734065 & -38.306 & 55.6513 \\
\hline \multirow[t]{2}{*}{ Startle Mean Delta X } & Equal var assumed & 4.210 & 0.051 & 0.676 & 25 & 0.505 & 56.054698 & 82.916579 & -114.71 & 226.824 \\
\hline & Equal var not assumed & & & 0.691 & 20.162 & 0.498 & 56.054698 & 81.162017 & -113.15 & 225.268 \\
\hline \multirow[t]{2}{*}{ Baseline Mean of Mean } & Equal var assumed & 1.056 & 0.314 & 1.415 & 25 & 0.169 & 11.130379 & 7.863956 & -5.0657 & 27.3264 \\
\hline & Equal var not assumed & & & 1.403 & 22.789 & 0.174 & 11.130379 & 7.935963 & -5.2948 & 27.5555 \\
\hline \multirow[t]{2}{*}{ Startle Mean of Mean } & Equal var assumed & 6.752 & 0.015 & 0.569 & 25 & 0.575 & 18.123128 & 31.8684041 & -47.511 & 83.7573 \\
\hline & Equal var not assumed & & & 0.574 & 24.260 & 0.571 & 18.123128 & 31.5636808 & -46.984 & 83.2303 \\
\hline
\end{tabular}


on the anger/frustration, fear, inhibitory control, and shyness subscales of the EATQ-R and TMCQ, and amplitude (or extent of muscle activity) of startle response was examined. The subscales from these parent-questionnaires were designed specifically to measure emotional sensitivity and reactivity. Correlation analysis was employed to test for statistical significance.

\section{Mean normalized RMS amplitude and latency of startle responses}

With regard to research question one and two, results revealed no significant differences between startle response amplitude or latency in CWS and CWNS. Tables 3 and 4 present RMS amplitude (Mean) and latency (Delta X) data for children who do and do not stutter.

Results of the Independent Sample t-tests revealed no statistically significant difference at the 0.05 level of confidence between the RMS amplitude and stuttering variable. The mean normalized startle for CWS of 1.7522 is almost identical to the mean normalized startle response of CWNS, 1.7468. Levine's Test revealed a $p$ value of 0.008 , indicating no significant relationship between the stuttering and amplitude variables. Additionally, no significant difference was present be- tween latency of response and the stuttering variable. The mean latency response of CWS was 295.800, while the mean latency response of CWNS was 239.746. CWS and CWNS do not have significantly different startle responses in terms of amplitude or latency, according to the findings of this study.

\section{Habituation of startle reponses}

With regard to research question three, results revealed no significant difference in habituation of startle responses between CWS and CWNS. Tables 5-9 present habituation data for children who do and do not stutter.

For each child in the two groups, the amplitude of their first response was compared to the amplitude of their last response in order to investigate the habituation of CWS compared to CWNS. Habituation rate is the decrease in response to a stimuli after repeated presentations. Typically, a reduction in response is present when exposed to multiple stimuli (i.e., the first presentation of the stimulus in trial one is expected to be somewhat more startling to an individual than the subsequent 15th presentation of the stimulus). The mean differences in these responses (first response and last response) were compared between groups. A Paired Sample t-test was used to analyze this data. Results of the Paired Sample t-tests

Table 5. Habituation of Startle Response in CWS and CWNS

\begin{tabular}{llcccc}
\hline & & Mean & $N$ & Std. Deviation & Std. Error Mean \\
\hline Pair 1 & first response & 215.17141 & 27 & 96.986371 & 18.665036 \\
& last response & 152.86556 & 27 & 68.407809 & 13.165089 \\
\hline
\end{tabular}

Table 6. Paired Samples Correlations

\begin{tabular}{lcccc}
\hline & & $N$ & Correlation & Sig. \\
\hline Pair 1 & first response \& last response & 27 & 0.932 & 0.000 \\
\hline
\end{tabular}

Table 7. Paired Samples Test

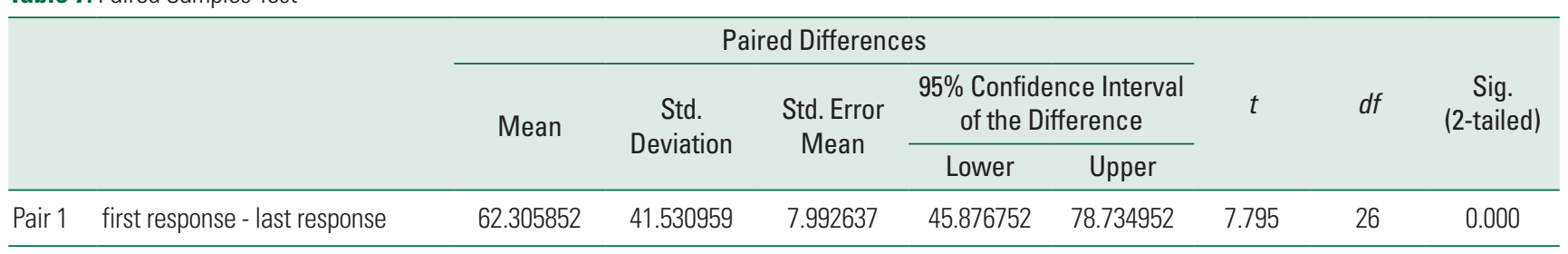

Table 8. Group Statistics

\begin{tabular}{cccccc}
\hline & Stutter (Y/N) & $N$ & Mean & Std. Deviation & Std. Error Mean \\
\hline Habituation & $Y$ & 14 & 51.1498 & 42.99495 & 11.49088 \\
& $N$ & 13 & 74.3201 & 37.85402 & 10.49882 \\
\hline
\end{tabular}


Table 9. Independent Samples Test

\begin{tabular}{|c|c|c|c|c|c|c|c|c|c|c|}
\hline & & \multicolumn{2}{|c|}{$\begin{array}{c}\text { Levine's Test for } \\
\text { Equality of Variances }\end{array}$} & \multicolumn{7}{|c|}{ t-test for Equality of Means } \\
\hline & & \multirow[t]{2}{*}{$F$} & \multirow[t]{2}{*}{ Sig. } & \multirow[t]{2}{*}{$t$} & \multirow[t]{2}{*}{$D f$} & \multirow[t]{2}{*}{$\begin{array}{c}\text { Sig. } \\
\text { (2-tailed) }\end{array}$} & \multirow[t]{2}{*}{$\begin{array}{c}\text { Mean } \\
\text { Difference }\end{array}$} & \multirow[t]{2}{*}{$\begin{array}{l}\text { Std. Error } \\
\text { Difference }\end{array}$} & \multicolumn{2}{|c|}{$\begin{array}{c}95 \% \text { Confidence } \\
\text { Interval of the } \\
\text { Difference }\end{array}$} \\
\hline & & & & & & & & & Lower & Upper \\
\hline \multirow{2}{*}{$\begin{array}{r}\text { Difference } \\
\text { Calming }\end{array}$} & Equal variances assumed & 0.632 & 0.434 & -1.481 & 25 & 0.151 & -23.17029 & 15.64099 & -55.38352 & 9.04294 \\
\hline & Equal variances not assumed & & & -1.489 & 24.937 & 0.149 & -23.17029 & 15.56488 & -55.23085 & 8.89026 \\
\hline
\end{tabular}

Table 10. Correlation of Normalized Startle Response and Parent-Report Temperament Data for CWS and CWNS

\begin{tabular}{|c|c|c|c|c|c|c|}
\hline & & Normalized Startle & Anger/ Frustration & Fear & Inhibitory Control & Shyness \\
\hline \multirow[t]{3}{*}{ Normalized Startle } & Pearson Correlation & 1 & 0.069 & -0.310 & -0.102 & -0.075 \\
\hline & Sig. (2-tailed) & & 0.738 & 0.123 & 0.620 & 0.710 \\
\hline & $\mathrm{N}$ & 27 & 26 & 26 & 26 & 27 \\
\hline \multirow[t]{3}{*}{ Anger/Frustration } & Pearson Correlation & 0.069 & 1 & 0.561 & -0.440 & 0.274 \\
\hline & Sig. (2-tailed) & 0.738 & & 0.000 & 0.006 & 0.096 \\
\hline & $\mathrm{N}$ & 26 & 38 & 37 & 37 & 38 \\
\hline \multirow[t]{3}{*}{ Fear } & Pearson Correlation & -0.310 & 0.561 & 1 & -0.182 & 0.014 \\
\hline & Sig. (2-tailed) & 0.123 & 0.000 & & 0.287 & 0.934 \\
\hline & $\mathrm{N}$ & 26 & 37 & 37 & 36 & 37 \\
\hline \multirow[t]{3}{*}{ Inhibitory Control } & Pearson Correlation & -0.102 & -0.440 & -0.182 & 1 & -0.285 \\
\hline & Sig. (2-tailed) & 0.620 & 0.006 & 0.287 & & 0.083 \\
\hline & $\mathrm{N}$ & 26 & 37 & 36 & 38 & 38 \\
\hline \multirow[t]{3}{*}{ Shyness } & Pearson Correlation & -0.075 & 0.274 & 0.014 & -0.285 & 1 \\
\hline & Sig. (2-tailed) & 0.710 & 0.096 & 0.934 & 0.083 & \\
\hline & $\mathrm{N}$ & 27 & 38 & 37 & 38 & 39 \\
\hline
\end{tabular}

revealed no statistically significant difference at the 0.05 level of confidence between the habituation and stuttering variable. The mean habituation for CWS is 51.149 and the mean habituation response of CWNS is 74.320. Levine's Test revealed a $p$ value of 0.434 , indicating no significant relationship between the stuttering and habituation variables. CWS and CWNS do not have significantly different habituation rates of startle responses, according to the findings of this study.

\section{Correlation of startle response and parent-report questionnaire}

In regard to research question four, no significant correlation was found between scores on individual subscales of the temperament exam and the amplitude of startle responses (normalized).

These results indicate that no significant correlation is present between scores on an individual subscale of the tempera- ment exam and the amplitude of startle response (normalized). A positive correlation (0.069) between normalized startle response and subscale scores of anger/frustration is present; however, this is not generalizable secondary to sample size. Additionally, normalized startle response and fear have a weak negative correlation $(-0.310)$. Shyness and inhibitory control approximate no linear relationship with the normalized startle response of these individuals. Sample size also limits the generalizability of findings that might result from a predictive regression analysis of scores on the temperament scales and amplitude of startle responses.

\section{DISCUSSION}

Many past investigations into the relationship between a sensitive temperament and stuttering appear to reinforce the notion of a link between these two constructs. There is evidence 
of increased positive and negative reactivity in individuals who stutter, as data indicate people who stutter exhibit heightened feelings of anxiousness, nervousness, helplessness, as well as dependence, introversion, negative social and/or communication attitudes, withdrawal, lower social competence, and mild social maladjustments $[19,20]$. Although these studies are in agreement with a positive relationship between sensitive temperament and stuttering, they fail to measure temperament using the methodological rigor of the neurosciences. The literature review provides only a small number of studies that employ neurophysiological measures of temperament in their methodology. More commonly, data is collected, and conclusions are drawn based upon pencil-and-paper questionnaires and/or self-report. Moreover, when EMG data has been employed, as with the Guitar [36] study, the data was not normalized and thus the findings are unreliable. Normalization allows data across participants to be compared on a common scale, as participant's response amplitudes are expressed in terms of percentage of baseline response. For the purposes of the present investigation, mean amplitude data was normalized. This methodological aspect is critical to accurately detect the intensity of reactions across subjects, and draw meaningful conclusions. Therefore, researchers must employ normalization procedures when interpreting EMG activity level, by relating it to some reference activity level obtained at that particular muscular injunction, in this case baseline eyeblinks under natural conditions. Previous research lacking data normalization cannot accurately represent the amplitude of the startle response comparatively across individuals, leading to the possibility of unreliable conclusions.

To date, there has yet to be a physiological study of temperament conducted within the population of school-aged children who stutter. Information from this study could objectively differentiate characteristics of stuttering intrinsically related to reactivity versus self-regulation strategies adopted by the autonomic nervous system as coping mechanisms.

Considering the aforementioned available research on this topic, the main objectives of this study were to determine the relationship between the reactivity/sensitive of school-age CWS, using reliable methods of neurophysiology (the acoustic startle response) as well as scores on a standardized temperament scale. More specifically, this research sought to use EMG data to examine and meaningfully interpret the mean amplitude of startle response scores, mean latency of startle response scores, habituation rate (which is the decrease in response to a stimuli after repeated presentations) of startle re- sponse score, and correlation between scores on the anger/ frustration, fear, inhibitory control, and shyness subscales of the EATQ-R and TMCQ and amplitude (or extent of muscle activity) of startle responses.

Improving on methodologies of past studies, this present investigation employed: (a) the collection of a thorough background of testing, history, records, and parent interview for each participant, (b) carefully defined groups represented by CWS persistently, based upon clearly specified parameters of stuttering, with the gender ratio well represented, (c) clearly delineated and replicable EMG procedures, (d) normalization of EMG data, and (e) neurophysiological measures of temperament combined with caregiver temperament questionnaire. Thus, although the groups were small, a wealth of focused and precise data was gleaned from each of these children. Discussions pertaining to the results of each research question are presented first, followed by a section on theoretical considerations.

\section{Differences in mean amplitude}

One of the main findings in this present study is the lack of significant differences between the group of CWS and CWNS with regard to mean amplitude of startle response. These findings are in direct contradiction to several studies that have reported higher levels of trait anxiety or "nervousness" in adults who stutter $[19,36]$. This difference may be due to the cumulative effect of negative speaking experiences over time, as the aforementioned studies were exclusive to an adult population. With regard to the various subtypes of stuttering, many current theoretical models include temperament as significantly influencing the developmental pattern of stuttering. As stated earlier, temperament refers to a set of behavioral characteristics or reactions that are biologically-based, present from infancy, and relatively stable over time and across contexts $[75,76]$. In other words, as Rothbart defined it, temperament is a constitutional relationship between emotional reactivity and emotional regulation. According to this definition, the individual differences in reactive and regulation manifest in domains of emotion, attention, and activity [4]. However, personality is defined as a construct less innate and can be acquired and fluid over time, manifesting in an individual's innate temperament in a fluctuating environment full of variables [77].

Considering the previous nature of research in this area was self-report and questionnaire, it is plausible that findings related to anxiety and reactivity of individuals who stutter are 
truly describing personality traits of these individuals rather than innate temperament or hard-wired characteristics. In fact, this current study, when combined with the aforementioned adult research, might suggest that no difference is present innately in the temperament of individuals who stutter; however, over time negative experiences and environmental factors stockpile. As a result, one becomes a non-fluent adult who is more anxious than their fluent peer.

Additionally, the current findings from the present investigation seem to align with the previously mentioned pediatric study by Ortega [21] who examined salivary cortisol and alpha-amylase, two independent measures of stress response, in children who stutter. Ortega found children who stutter did not possess salivary cortisol levels outside of the normal limits expected for their ages. However, cortisol samples upon awakening, and in the afternoon, were significantly different in children who stutter, indicating CWS have more variable levels of cortisol throughout the day. Though cortisol and alpha-amylase levels were within normal limits, daily circadian rhythms were generally disrupted for both biomarkers [21]. In the Ortega study and this current study, though the markers of temperament were different (one biochemical and one neurological), both suggest no significant difference between CWS and CWNS in static innate anxiety or trait anxiety. However, Ortega [21] shows a higher fluctuation in stress response throughout the day for CWS, which would also suggest these children are reacting more sensitively to environmental stressors though no innate differences in temperament sensitivity are present.

An additionally study on adults found that people who stutter produced greater increases in salivary cortisol when compared to their normally fluent peers under periods of high general stress [24]. Further posing the question, are CWS conditioned over time to react more sensitively to stress, though they have no significant different in temperament than their fluent peers? If so, why is this important? If the issue of sensitivity/reactivity and the resulting anxiety is not innate, then preventing the stockpile of negative experiences, the accumulation of anxiety ridden automated responses, and maintaining the healthiest cognitive behaviors possible surrounding stuttering is then the responsibility of the treating clinician.

\section{Mean latency of response}

As stated earlier, one reason for interest in the relationship between latency and stuttering was to determine if the duration of the startle response was longer in CWS than their normally fluent peers. Results of this current investigation revealed no significant difference between the latency of startle responses in CWS and CWNS. Homeostasis is controlled by the parasympathetic nervous system. It is the ability to maintain, or return to, a constant and stable internal state, in response to external environmental changes or stressors. These two groups are returning to homeostasis, after a startling event (stressor), at similar rates. CWS do not have a startle response that is greater in duration (latency) than his/her fluent peer, further indicating that the reactiveness of their temperament is not differing to a degree that is significant.

\section{Current findings related to a DD-S model}

This finding is of note when considering the aforementioned Dual Diathesis Stress Model of Stuttering (DD-S), which applies Monroe and Simmons' [78] notion of a "stressor" activating a "diathesis." The DD-S model explains environmental activation of a genetic predisposition, and can be applied to several various types of development. Walden et al. [79] applied this DD-S model to stuttering, focusing on the linguistic and emotional processes influencing stuttering development and maintenance. Using this model, Walden et al. [79] explain the parasympathetic nervous system's response to a stressor as it pertains to stuttering.

This model defines diathesis as the proclivity to respond in a particular way; therefore, Walden et al. [79] relate diathesis to temperamental as well as linguistic responses in this model. Stress is defined as a stimulus that activates a situational (emotional) response and emotional responses are distinguished as trait-like or state-like. Temperamental emotionality is a relatively stable, trait-like aspect of emotional responding, which is considered a diathesis in this model. Situational emotions are relatively variable, state-like aspects of emotional responding, here considered to be a response to stress. A stressor is anything that pushes the autonomic nervous system out of homeostasis. Subsequently, a stress response, "activates specific cognitive and affective processes and their central nervous system underpinnings" [80]. "Effects of psychological stressors on physiological system are highly variable" [80]. Therefore, in the presence of a stressor (linguistic or emotional), the autonomic nervous system, strongly influenced by limbic structures, is pushed out of homeostasis in an individual who stutters. As a result, stress responses (emotional or linguistic) are activated. Thus the temperamental predisposition (diathesis) of the individual is activated. According to the findings in this study, CWS are returning to ho- 
meostasis at the same rate as their fluent peers after their stress response is activated. In the presence of a stressor, in this case a burst of white noise, the autonomic nervous system in the participant was pushed out of homeostasis as evidenced by their startle response. The latency, or duration, of the startle response represented how long it took each child to return to baseline or homeostasis. The CWS and CWNS did not significantly differ in the latency (duration) of their startle responses. These children were returning to homeostasis in similar manners subsequent to an environmental stressor.

When stress activates a diathesis, the underlying emotional temperament of the individual is manifested in a situational, emotional response. When a stressor activates a diathesis, the result may be an increase in the frequency of a situation emotional response, and thus an increase in the frequency of stuttering. Underlying emotional diathesis (i.e., temperament) has been shown to distinguish children who stutter from children who do not stutter, and influences the development of stuttering in a variety of ways. Situational emotional responding is more variable, thereby contributing to the instance of stuttering speech events in a variety of ways [79].

Relatively stable diatheses (emotional or linguistic) can be activated by relatively variable stressors (emotional or linguistic) to contribute to relatively variable stuttering. In this way, the DD-S Model of stuttering accounts for the variable nature of stuttering, considering the trait-like nature of temperamental predisposition.

The findings of this current investigation can be viewed in tandem with this model of stuttering. This study elicited a stress response in CWS using bursts of white noise, thus "activate(ing) specific cognitive and affective processes and their central nervous system underpinnings" [80]. By stressing the diathesis, the underlying emotional temperament of the individual, and finding there to be no statistically significant difference in reactivity, this parsed out the stable temperamental diathesis (trait-like) from the variable situational emotional response (state-like). By doing so, this helped to rule out temperament as a significant difference between CWS and CWNS, as their latency of response indicated no significant difference of the parasympathetic nervous system's and return to homeostasis. This finding seems to pinpoint the situational emotional response as primarily responsible for differences between CWS and CWNS. As stated previously, this result would indicate state-like aspects of emotions to be the differing factor between CWS and their fluent peer. This would agree with the 2012 study by Walden, Frankel, Buhr,
Johnson, Conture, and Karass, who found that situation emotional responding (state-like aspects of emotion which are more variable) were contributing to the instance of stuttering speech events in a variety of ways. While the findings of this study would disagree with the portions of the DD-S model that suggest underlying emotional diathesis (i.e., temperament) has been shown to distinguish children who stutter from children who do not stutter, and influences the development of stuttering in a variety of ways.

Furthermore, clinical implications of this finding are encouraging. If the significant difference(s) between CWS and CWNS lay within the emotional response rather than the innate temperament of the child, then working to change environmental variables and manage negative thoughts and behaviors using cognitive strategies, even counseling referrals when necessary, could gravely impact the instance of stuttering speech events for CWS. This research suggests that CWS are not operating from a disadvantaged temperament that is more sensitive to speaking failures and environmental stressors. The playing field is level, so to speak, for the CWS and the CWNS as far as innate temperamental disposition. This is encouraging, as stuttering is not a single disorder -- a pathognomic monolith [1]. It is complex, multilevel and dynamic linguistically. It involves central speech programming, as well as emotional and cognitive processes interacting to ultimately affect the motor function necessary for speech production. With of all the variables co-mingling, knowing that a sensitive/ reactive temperament is not additionally "working against" these CWS, is quite a meaningful and positive finding.

\section{Mean of habituation response}

One interesting finding of this study is the lack of significant difference between the group of CWS and CWNS in mean habituation of startle response. Habituation rate is the decrease in response to a stimuli after repeated presentation, and the repetition component of this measure key significance. In this experiment, the multiple noise bursts served as the repeated stimuli. Both the CWS and CWNS showed a decrease in startle amplitude from the initial noise burst compared to the final noise burst at a rate that was not significantly different from one another. In other words, the CWS and the CWNS were displaying decreases in reaction to repeated startling stimuli to a similar degree, as it was becoming more familiar and less novel.

The clinical implications of this finding can be related to components of classical conditioning. Inappropriate activa- 
tion of the right hemisphere during speaking tasks in individuals who stutter has been confirmed in multiple studies dating back to the aforementioned SPECT studies of the 1980's. The inappropriate activation of right hemispheric emotional centers during speaking tasks has profound implications for people who stutter in that these structures have deep-seated neurological connections with the limbic system, a structure highly susceptible to classical conditioning, as well as the hippocampus, which is the sub-cortical seat for memory. This sheds light on aspects of emotionality and emotional learning that may be influencing disfluent speech. Repeated emotional responses can be learned and hardwired into the neurological reactions of individuals with fluency disorders.

This repetition causes emotional pathways to be established that produce fear, anxiety, or disappointment as familiar, conditioned responses. Compounding the problem is the fact that frequent experiences with fluency failures are not uncommon for individuals who stutter. The negative experiences create additional opportunities for repeated negative reactions. Each fluency failure reinforces beliefs that for this individual, speaking is difficult, and should be feared, and thus a cyclical effect occurs as each new experience confirms this negative belief system [35].

In light of this neurological information, the findings of this study are encouraging as they suggest the innate temperament of the CWS does not leave them more susceptible to a classically conditioned/hardwired negative emotional response. The CWS are responding to repeated exposure of averse stimuli with the same gradient of response as their fluent peers, on a neurologic level. While each negative experience and fluency failure is impacting the child's cognitive belief system and fear response system as described above, the CWS is not responding to the repeated averse stimuli to a greater degree than a CWNS might respond, according to the results of this study. The CWS is habituating to the repeated averse stimuli similarly to the CWNS. This may mean that the CWS is not, therefore, at a disadvantage for mitigating his/her fear response on a temperamental level, which would have compounded the complexity of the child's struggle.

Therefore, if the CWS and CWNS have a similar baseline of susceptibility to neurologically hardwiring emotional responses in the presence of repeated averse stimuli, then the conditioned fear response is less exclusive to the CWS and may be more manageable from a clinical standpoint. If the repeated experience is being hardwired into the child, but the child's innate temperament is not a primary contributing fac- tor, then clinically targeting more malleable factors such as the child's environment, external support system, and cognitive belief system may be a more powerful approach to fluency than previously suspected. Working to minimize the child's negative speaking experiences and neutralize the resulting internal reactions seems more surmountable, with the understanding that an ingrained sensitive/reactive temperament may not be a confounding factor.

\section{Correlation between temperament subscales and startle responses}

Lastly, it is of note that no significant correlation is present between scores on an individual subscale of the temperament exam and the amplitude of startle response (normalized). Previously, studies of temperament have relied heavily on parent questionnaire and self-report. While these measures provide important information regarding an individual's predispositions and temperamental tendencies, a level of human error is present. Additionally, past studies have revealed large discrepancies between parent-report and child-report on measures of quality of life [47], relationship quality [48], psychosocial health domains [49] as well as emotional and mental health domains [50]. Self-report measures also are subject to confounding variables which are difficult to identify and control, such as cognitive perspective, situational perspective, and the stable cognitive profile of the individual [51]. The lack of correlation present in this study between measures of parent report and physiological measures of temperament further confirm the weakness of previous research based solely upon measures of self/parent report. It should be noted that the sample size limits the generalizability of findings that might result from a predictive regression analysis of scores on the temperament scales and amplitude of startle responses.

\section{Theoretical implications}

The findings of this present study shed only little light on the complex issue of temperament and stuttering. Inasmuch as there were some noteworthy findings, these were limited by sample size and seemed only to pose additional questions. As stated earlier, investigating dimensions of temperament might further highlight the importance of environmental factors of individuals who stutter. Unraveling these environmental components would allow clinicians to create therapeutic as well as home environments that lend themselves to the facilitation of neuroplasticity and adaptability within the child, subsequently affecting his speech and language from a neurological 
perspective. Treatments focusing on creating an environment that is positive and encouraging would aid in the development of a less inhibited temperament while possibly facilitating confident and assertive behavior as the child responds more constructively to his/her environment. Additionally, approaches that concentrate on providing enjoyable and rewarding communication experiences, would facilitate a reduction in fear and freezing behaviors associated with speaking for individuals who stutter. Encouraging approach behavior and confrontation of feared words or contexts would help facilitate left hemisphere activity as well. To this point, brain imaging studies of adults before and after treatment $[81,82]$ have shown that successful treatment is associated with increased activation of left hemisphere areas which were previously inactive, as well as reductions in the over-activation of the right hemisphere.

Data from this study suggest that any temperamental difference between CWS and CWNS is not inherent. This agrees with previous research showing tense responses, escape and avoidance behavior, and negative feelings/attitudes (while a product of a temperament) are somewhat learned responses, which are modifiable by new learning. Therefore, understanding the individual nuances of temperament within children who stutter would provide information for the development of individualized treatments to facilitate new learning, as well as tailored coping strategies to help children effectively deal with speech disruptions. However, these temperamental nuances are not innately differing from the CWS's fluent peer.

Additionally, findings regarding neurophysiological components of temperament also may facilitate problem solving relative to environmental and emotional influences that are exasperating a child's temperament and/or disfluent speech. These environmental and emotional factors could then be targeted in intervention in order to establish holistic treatment and holistic success.

\section{Limitations of present investigation}

Even though this investigation was thorough and precise, addressing many methodological shortcomings of previous research by employing a meticulous research design which included normalization of data, certain limitations should be noted.

1. The composition of participants in this study was balanced demographically, accounting for the 13:1 stuttering gender ratio [3]. Nevertheless, an increase in overall sample size would improve the statistical power in future studies and make conclusions more generalizable.

2. Though thoroughly educated, trained, and supervised on electromyography, the researcher was the primary collector and analyzer of EMG data in this study. All data was tediously examined multiple times; however, elements of human error exist as the nature of the data interpretation process required a human analysis component.

3. Additionally, the Temperament in Middle Childhood Questionnaire (TMCQ) [66] and the Early Adolescence Temperament Questionnaire-Revised, Parent Report (EATQ-R) [67] were administered in order to measure individual temperament. Even though the temperament measures were the best-fit for this current study because they explicitly test the three dimension of temperament: surgency/extroversion, negative affect, and effortful control, one test of temperament given to all participates would have been best practice, had a reputable one appropriate for individuals between 8 to 14 years of age been available.

\section{Future research}

\section{Sample size}

Though this study's sample size is comparable to similar studies in this field that employed neurophysiological methodology, the sample size still lacked power for generalization. Due to time and resource constraints of this dissertation study, the sample size was limited to 28 school-age children. Future studies should include a larger sample size (100-300 participants) in order to increase the statistical power of the results, making the findings more generalizable.

\section{Trait vs. State emotional responses}

Future studies should try to parse out trait verses state emotional responses. Anxiety is a multidimensional construct [83]. Trait anxiety is defined as a person's constitutional level of anxiety, which is stable across a variety of situations, while state anxiety is defined as a condition-specific or situationspecific level of anxiety. Ortega [21], has shown a higher fluctuation in stress response throughout the day for CWS, which would also suggest these children are reacting more sensitively to environmental stressors though no innate differences in temperament sensitivity are present. Research confirms that adults with chronic stuttering have elevated levels of anxiety [84]. The question becomes, at what point in a child's development into adolescence and adulthood does the anxiety that is secondary to stuttering begin to exceed normal limits? Many adult disorders begin to development in childhood, 
thus understanding this question is crucial $[84,85]$. A recent meta-analysis of almost 1,300 adults with chronic stuttering found the majority of adults who stutter have at least moderately elevated trait anxiety and substantially elevated social anxiety compared to non-stuttering controls [86]. Research is consistently shows that CWS do not have elevated levels of trait anxiety. Craig and Hancock [87] tested trait and state anxiety in 96 CWS and 104 of their age matched peers, concluding CWS were no more anxious than CWNS and their anxiety levels were within normal limits as a whole. Hancock [88] followed up on this cohort and found a continued reduction in anxiety levels over time, following stuttering treatment. Additionally, Davis et al. [89] tested trait anxiety in school aged CWS and found no significant difference when compared to their fluent peers. Further research such as this study, grounded in neurophysiology and examining trait and state anxiety of CWS, is warranted to determine at what point in development anxiety in stuttering is increasing over time to exceed normal limits in individuals who stutter. Future studies should also be methodologically designed to parse out trait and state anxiety, as well as temperament and/or personality from emotionally learned coping mechanism/responses.

Overall, it is hoped that this study will stimulate further research into the area of temperament and stuttering. More information is necessary to clarify this relationship and to discover the most appropriate and effective means of treating fluency disorders in children. It remains to be determined if certain temperamental differences are inherent to individuals who stutter, or perhaps a result of the stuttering itself. Pairing both physiological and descriptive research designs that examine temperamental differences in children who stutter and children who do not stutter is imperative to answering important questions in this area of study. Specifically, information about the interaction between temperamental characteristics and persistent stuttering in children is needed. As children age, the possibility of natural recovery is diminishing, the nature of treatment is subsequently shifting. Focusing research on persistent stuttering within the school-age population is critical. Treating school-age children who stutter focuses on a more comprehensive understanding of the child's experience of stuttering. As the child ages, stuttering can become an increasingly greater part of his/her communication and life, and the impact begins to grow exponentially. A key contributing factor in this scenario is the child's reaction to both the impairment as well as the resulting participation limitations. Therefore, understanding key components of personality and temperament, exposure to repeated negative experiences, emotional processing, and the child's environment (both real and perceived) are a crucial for the future of this field.

\section{REFERENCES}

1. Yairi E, Ambrose NG. Early childhood stuttering: by clinicians for clinicians. Austin, TX: Pro-Ed Inc Publishers; 2004.

2. Weber-Fox C, Spencer R, Cuadrado E, Smith A. Development of neural processes mediating rhyme judgments: phonological and orthographic interactions. Developmental Psychobiology. 2003; 43:128-145.

3. Yairi E, Seery CH. Stuttering: foundations and clinical applications, 2nd Edition. Pearson Publishing. 2015.

4. Rothbart MK, Hwang J. Temperament and the development of competence andmotivation. In A.J. Elliot \& A.C. Dweck (Eds.), Handbook of competence and motivation. New York: Guilford Press. 2005;167-184.

5. Kail RV, Barnfield A. Children and their development, second canadian edition with my development lab. Toronto: Pearson Education Canada; 2011.

6. Fowlie GM, Cooper EB. Traits attributed to stuttering and nonstuttering children by their mothers. Journal of Fluency Disorders. 1978;3:233-245

7. Schwenk K, Conture EG, Walden T. Reaction to background stimulation of preschool children who do and do not stutter. Journal of Communication Disorders. 2007; 40:129-141.

8. Johnson K, Walden T, Conture EG, Karass J. Spontaneous regulation of emotions in preschool children who stutter: preliminary findings. Journal of Speech, Language, and Hearing Research. 2010;53:1478-1495.

9. Karrass J, Walden T, Conture E, Graham C, Arnold H, Hartfield K, et al. Relation of emotional reactivity and regulation to childhood stuttering. Journal of Communication Disorders. 2006;39:402-423.

10. Embrechts M, Ebben H, Franke P, van de Poel C. Temperament: a comparison between children who stutter and children who do not stutter. In HG Bosshardt, JS Yaruss, HFM Peters (Eds.), Fluency disorders: theory, research, treatment and self help. Proceedings of the Third World Congress on Fluency Disorders in Nyborg, Denmark. 2000;557-562.

11. Anderson JD, Pellowski MW, Conture EG, Kelly EM. Temperamental characteristics of young children who stutter. Journal of Speech, Language, and Hearing Research. 2003;46:1221-1233.

12. Karass J, Braungart-Rieker JM. Parenting and temperament as interacting agents in early language development. Parenting: Science and Practice. 2003;3:235-259.

13. Conture EG. Young stutterers' speech production. In HFM Peters, W Hulstijn, CW Starkweather (Eds.), Speech motor control and stuttering. 1991;365-384. Amsterdam: Excerpta Medica.

14. Peters TJ, \& Guitar B. Stuttering: an integrated approach to its nature and treatment. Baltimore: Williams \& Wilkins; 1991.

15. Guitar B. Stuttering: an integrated approach to its nature and 
treatment (2nd Ed.). Baltimore: Williams and Wilkins; 1998.

16. Guitar B. Emotion, temperament and stuttering: some possible relationships. In K Baker, L Rustin, F Cook (Eds.), Proceedings of the Fifth Oxford Dysfluency Conference. 2000;1-6. Leicester, England: Baker.

17. Craig A. An investigation into the relationship between anxiety and stuttering. Journal of Speech and Hearing Disorders. 1990;55: 290-294.

18. Craig A, Hancock K, Tran Y, Craig M. Anxiety levels in people who stutter: a randomized population study. Journal of Speech, Language, and Hearing Research. 2003;46:1197-1206.

19. Ezrati-Vinacour R, Levin I. The relationship between anxiety and stuttering: a multidimensional approach. Journal of Fluency Disorders. 2004;29:135-148.

20. Messenger M, Onslow M, Packman A, Menzies R. Social anxiety in stuttering: measuring negative social expectancies. Journal of Fluency Disorders. 2004;29:201-212.

21. Ortega A. Stuttering behavior and physiological stress profiles: a preliminary investigation of school-age children. Journal of Fluency Disorders. 2011;36:268-273.

22. Arnold H, Conture E, Key A, Walden T. Emotional reactivity, regulation and childhood stuttering: a behavioral and electrophysiological study. Journal of Communication Sciences and Disorders. 2011;44:276-293.

23. Leanderson R, Levi L. A new approach to the experimental study of stress and stuttering. Acta Otolaryngologica. 1967;224:311-316.

24. Blood GW, Blood IM, Bennett S, Simpson KC, Sussman EJ. Subjective anxiety measurements and cortisol responses in adults who stutter. Journal of Speech and Hearing Research. 1994;37:760768.

25. Despert JL. Psychosomatic study of fifty stuttering children: I. social, physical and psychiatric findings. American Journal of Orthopsychiatry. 1946;16:100-113.

26. Weber CM, Smith A. Autonomic correlates of stuttering and speech assessed in a range of experimental tasks. Journal of Speech and Hearing Research. 1990;33:690-706.

27. Kraaimaat F, Janssen P, Brutten GJ. The relationship between stutterers' cognitive and autonomic anxiety and therapy outcome. Journal of Fluency Disorders. 1988;13:107-113.

28. Guyton AC, Hall JE. Textbook of medical physiology. Jackson, MI: W. B. Saunders Publishing Co.; 1996.

29. Costa D, Antoniac M, Berghianu S, Marinescu R, et al. Clinical and paraclinical aspects of tetany in stuttering. Activitas Nervosa Superior. 1986;28:156-158.

30. Alm P. Stuttering and basal ganglia circuits: a critical review of possible relations. Journal of Communication Disorders. 2004;37: 325-369.

31. Brown S, Ingham RJ, Ingham JC, Laird AR, Fox PT. Stuttered and fluent speech production: an ALE meta-analysis of functional neuro-imaging studies. Human Brain Mapping. 2005;25:105-117.

32. Pool KD, Devous MD, Freeman FJ, Watson BC, Finitzo T. Regional cerebral blood flow in developmental stutterers. Archives of Neurology. 1991;48:509-512.
33. Ingham RJ, Fox PT, Ingham JC. Brain image investigation of the speech of stutterers and nonstutters. ASHA. 1994;36:188.

34. Wu JC, Maguire G, Riley G, Fallon J, LaCasse L, Chin S, Klein E, Tang C, Cadwell S, Lottenberg S. A positron emission tomography [18F] deoxyglucose study of developmental stuttering. Neuroreport. 1995;6:501-505.

35. Logan R. Three dimensions of stuttering: neurology, behavior, and emotion. Whurr Publishers; 2007.

36. Guitar B. Acoustic startle responses and temperament in individuals who stutter. Journal of Speech, Language, and Hearing Research. 2003;46:233-240.

37. Alm P, Risberg J. Stuttering in adults: the acoustic startle response, temperamental traits, and biological factors. Journal of Communication Disorders. 2007;40:1-41.

38. Hoffman HS, Searle JR. Acoustic variables in the modification of startle reaction in the rat. Journal of Comparative and Experimental Psychology. 1965;60:53-58.

39. Vrana SR, Spence EL, Lang PJ. The startle probe: a new measure of emotion? Journal of Abnormal Psychology. 1988;97:487-491.

40. Grillon C, Ameli R, Woods SW, Merikangas K, Davis M. Fear-potentiated startle in humans: effects of anticipatory anxiety on acoustic blink reflex. Psychophysiology. 1991;28:588-595.

41. Morgan CA, III Grillon C, Lubin C, Southwick SM, Steven M. Startle reflex abnormalities in women with sexual assault-related posttraumatic stress disorder. The American Journal of Psychiatry. 1997;154:1076-1080.

42. Taylor R M, Morrison LP. Taylor-Johnson temperament analysis manual. Thousand Oaks, CA: Psychological Publications; 1996.

43. Zimmerman G. Articulatory dynamics of fluent utterances of stutterers and nonstutterers. Journal of Speech and Hearing Research. 1980;23:95-107.

44. Zimmerman G. Articulatory behaviors associated with stuttering: a cineradiographic analysis. Journal of Speech and Hearing Research. 1980;23:108-121.

45. Zimmerman G. Stuttering: A disorder of movement. Journal of Speech and Hearing Research. 1980;23:122-136.

46. Davis M, Walker DL, Lee Y. Amygdala and bed nucleus of the stria terminalis: Differential roles in fear and anxiety measured with the acoustic startle reflex. In L Squire \& D Schacter (Eds.), Biological and psychological perspectives on memory and memory disorders. Washington, DC: American Psychiatric Press.1999.

47. Theunissen NCM, Vogels TGC, Koopman HM, Verrips GHW, Zwinderman KAH, Verloove-Vanhorick SP, Wit JM. The proxy problem: child report versus parent report in health-related quality of life research. Quality of Life Research. 1998;7:387-397.

48. Breuk RE, Clauser CA, Stams GJ, Slot NW, Doreleijers TA. The validity of questionnaire self-report of psychopathology and parentchild relationship quality in juvenile delinquents with psychiatric disorders. Journal of Adolescence. 2007;5:761-771.

49. Creemens J, Eiser C, Blades M. Factors influencing agreement between child self-report and parent proxy-reports on the Pediatric Quality of Life Inventory 4.0 (PedsQL) generic core scales. Health and Quality of Life Outcomes. 2006;4:58. 
50. Waters E, Stewart-Brown S, Fitzpatrick R. Agreement between adolescent self-report and parent reports of health and well-being: results of an epidemiological study. Child: Care, Health, and Development. 2003;29:501-509.

51. Brenner ND, Billy JOG, Grady WR. Assessment of factors affecting the validity of self-reported health-risk behavior among adolescents: Evidence from the scientific literature. Journal of Adolescent Health. 2003;33:436-457.

52. Berg WK, Balaban MT. Startle elicitation: stimulus parameters, recording techniques, and quantification. In M. Dawson, A. Schell, \& A. Bohmelt (Eds.), Startle modification: implications for neuroscience, cognitive science, and clinical science. New York: Cambridge University; 1999.

53. Dawson ME, Schell AM, Bohmelt AH. Startle Modification; implications for neuroscience, cognitive science, and clinical science. New York, New York: Cambridge University Press; 1999.

54. Anderson JD, Pellowski MW, Conture EG, Kelly EM. Temperamental characteristics of young children who stutter. Journal of Speech, Language, and Hearing Research. 2003;46:1221-1233.

55. Lewis KE, Goldberg LL. Measurements of temperament in the identification of children who stutter. European Journal of Disorders of Communication. 1997;32:441-448.

56. Oyler ME, Ramig PT. Vulnerability in stuttering children. Session presented at the annual convention of the American Speech-Language-Hearing Association, Orlando, FL; 1995.

57. Riley GD, Riley J. A revised component model for diagnosing and treating children who stutter. Contemporary Issues in Communication Sciences and Disorders. 2000;27:188-199.

58. Starkweather CW, Gottwald SR. The demands and capacities model. II: Clinical implications. Journal of Fluency Disorders. 1990;15:143-157.

59. Eggers K, De Nil LF, Van den Bergh BRH. Factorial temperament structure in stuttering, voice-disordered, and typically developing children. Journal of Speech, Language, and Hearing Research. 2009;52:1610-1622.

60. Alm PA. On the causal mechanisms of stuttering. Doctoral thesis. Dept. of Clinical Neuroscience, Lund University, Sweden; 2005.

61. Bloodstein O. A handbook on stuttering (5th Ed.). Clifton Park, NY: Thomson Delmar; 1995.

62. Conture EG. Stuttering: Its nature diagnosis and treatment. Boston: Allyn \& Bacon; 2001.

63. Johnson W, Associates. The onset of stuttering: Research findings and implications. Minneapolis: University of Minnesota; 1959.

64. Riley J. Stuttering Severity Instrument, Third Edition (SSI-3). 1994.

65. Fridlund AJ, Cacioppo JT. Guidelines for human electromyographic research. Psychophysiology. 1986;23:567-589.

66. Simonds J, Rothbart M. Temperament in middle childhood questionnaire (Version 3.0). Oregon: University of Oregon; 2004.

67. Ellis LK, Rothbart MK. Revision of the early adolescent temperament questionnaire. Manuscript in preparation; 1999, 2002.

68. Rothbart MK. Temperament and the pursuit of an integrated developmental psychology. Merrill-Palmer quarterly. 2004;50:492505.
69. Rothbart MK. Temperament, development and personality. Current Directions in Psychological Science. 2007;16:207-212.

70. Rothbart MK, Ahadi SA, Hershey KL, Fisher P. Investigations of temperament at 3-7 years: the children's behavior questionnaire. Child Development. 2001;72:1394-1408.

71. Victor SR, Baker JB. Hampton individual differences questionnaire. Paper presented at the Xth European Conference of Development Psychology, Uppsala, Sweden; 2001.

72. Victor JB, Rothbart MK, Baker SR. Manual for the child temperament and personality questionnaire (CTPQ). Hampton, VA: Hampton University; 2003.

73. Ablow JC, Measelle JR. Berkeley puppet interview: administration and scoring system manuals. berkeley, CA: University of California; 1993.

74. Hwang JY. Development of a temperament self-report measure for young children [Dissertation Abstract]. Dissertation Abstracts International: Section B: The Sciences and Engineering. 2002; 63(11B), 5550 .

75. Bates JE. Temperament in childhood. In John Wiley \& SonsKohnstamm, Geldolph A. (Ed); Bates, John E. (Ed); Rothbart, Mary Klevjord (Ed), Temperament in childhood. Oxford, England. 1989;3-26.

76. Wachs TD. The what, why, and how of temperament: a piece of the action. In L. Balter \& C. Tamis-LeMonda (Eds.), Child psychology: a handbook of contemporary issues. Philadelphia: Psychology Press. 1999;23-44.

77. Milon T, Milon CM, Meagher S, Grossman SD, Ramnath R. Personality disorders in modern life, 2nd Ed. New York, NY: Wiley \& Sons; 2004.

78. Monroe SM, Simons AD. Diathesis-stress theories in the context of life stress research: implications for the depressive disorders. Psychological Bulletin. 1991;110:406-425.

79. Walden T, Frankel C, Buhr A, Johnson K, Conture EG, Karass J. Dual Diathesis Stressor Model of Emotional and Linguistic Contributions to Developmental Stuttering. Journal of Abnormal Child Psychology. 2012;40:633-644.

80. Dickerson S, Kemeny M. Acute stressors and cortisol responses: A theoretical integration and synthesis of laboratory research. Psychological Bulletin. 2004;130:355-391.

81. De Nil LF, Beal D, Lafaille S, Kroll R, Crawley A, Gracco VL. The effects of simulated stuttering and prolonged speech on the neural activation patterns of stuttering and nonstuttering adults. Brain and Language. 2003;107:114-123.

82. Neumann K, Euler H, Wolff von Gudenberg A, Giraud A, Lanferman H, Gall V, Preibisch C. The nature and treatment of stuttering as revealed by fMRI: a within-and between-group comparison. Journal of Fluency Disorders. 2003;28: 381-410.

83. Iverach L, Menzies RG, O’Brian S, Packman A, Onslow M. The nature and treatment of stuttering as revealed by fMRI: a within-and between-group comparison. American Journal of Speech Language Pathology. 2011;20:221-232.

84. Smith KA, Iverach L, O'Brian S, Kefalianos E, Reilly S. Anxiety of children and adolescents who stutter: a review. Journal of Fluency 
Disorders. 2014;40:22-34.

85. Bayer JK, Rapee RM, Hiscock H, Ukoumunne OC, Mihalopoulous C, Wake M. Translational research to prevent internalizing problems early in childhood. Depression and Anxiety. 2011;28:50-57.

86. Craig A, Tran Y. Trait and social anxiety in adults with chronic stuttering: conclusions following meta-analysis. Journal of Fluency Disorders. 2014;40:35-43.

87. Craig A, Hancock K. Anxiety in children and young adolescents who stutter. Australian Journal of Human Communication Disor- ders. 1996;24:28-38.

88. Hancock K, Craig A, McCready C, McCaul A, Costello D, Campbell K. Two- to six year controlled-trial stuttering outcomes for children and adolescents. Journal of Speech, Language, and Hearing Research. 1998;41:1242-1252.

89. Davis S, Shisca D, Howell P. Anxiety in speakers who persist and recover from stuttering. Journal of Communication Disorders. 2007;40:398-417. 